\title{
Configurational Characteristics of Poly(oxy-1,1-dimethylethylene). I. Conformational Energies Estimated from the Analysis of the Dipole Moment Data of 1,2-Dimethoxy-2-methylpropane, a Monomer Model
}

\author{
Kazuhiro KATO, Kazuo ARAKI, ${ }^{*}$ and Akihiro ABE \\ Department of Polymer Chemistry, Tokyo Institute of Technology, \\ Meguro-ku, Tokyo 152, Japan. \\ *Department of Chemistry, Science University of Tokyo, \\ Kagurazaka, Shinjuku-ku, Tokyo 162, Japan.
}

(Received June 13, 1981)

\begin{abstract}
Dielectric measurements were carried out on 1,2-dimethoxy-2-methylpropane (DMMP), a monomer model for poly(oxy-1,1-dimethylethylene ) (PODME), in nonpolar solvents such as benzene, carbon tetrachloride, and cyclohexane. The values of the dipole moment $\left\langle\mu^{2}\right\rangle^{1 / 2}$ derived therefrom are $1.69,1.68$, and $1.61 \mathrm{D}$, respectively, at $25^{\circ} \mathrm{C}$. Theoretical calculations performed within the framework of the rotational isomeric state approximations were found to reproduce favorably these experimental results. Conformational energy parameters required in these calculations were estimated by using semiempirical potential energy expressions. The results of the analysis suggest that DMMP differs greatly from dimethoxyethane for which a gauche oxygen effect plays an important role in determining the relative stability of the isomeric states around the skeletal $\mathrm{C}-\mathrm{C}$ bond. Such an effect is almost entirely suppressed in the former compound: the trans state is preferred to the gauche states by about $0.5 \mathrm{kcal} \mathrm{mol}^{-1}$ in the conformational energy. Statistical weight matrices required for the analysis of the PODME chain have also been formulated.
\end{abstract}

KEY WORDS 1,2-Dimethoxy-2-methylpropane / Poly(oxy-1,1-dimethylethylene) / Dipole Moment / Potential Energy Calculation / Conformational Energy / gauche Oxygen Effect /

Poly(oxy-1,1-dimethylethylene) (PODME) is a crystalline polymer having a high melting point ( $c a$. $\left.175^{\circ} \mathrm{C}\right)^{1}$ and quite insoluble in conventional organic solvents. The polymer prepared from isobutene oxide by using diethyl zinc-water-cyclohexylamine catalyst is known to form a good elastic hard fiber on melt spinning. ${ }^{2}$ Some of the chemical and mechanical properties of the polymer have been reported. ${ }^{1-3}$ From the X-ray diffraction studies, Kaji and Sakurada ${ }^{4}$ concluded that the polymer chain possesses a somewhat distorted zigzag conformation in the crystalline state.

The conformational analysis of the PODME chain presented in this paper, and in those which will follow, constitutes a part of our studies ${ }^{5-7}$ on polyoxide chains having a general formula ${ } \mathrm{CH}_{2} \mathrm{C}\left(\mathrm{R}_{1}\right)\left(\mathrm{R}_{2}\right) \mathrm{O}_{x}$. In all these polymers, gauche
$\mathrm{O} \cdots \mathrm{O}$ interactions take place around the skeletal $\mathrm{C}-\mathrm{C}$ bond. The major purpose of our studies is to evaluate the gauche oxygen effect associated with these polymers in terms of the extra stabilization energies $(\Delta E)$, which have been defined ${ }^{5-8}$ as the difference between the conformational energies $\left(E_{\text {calcd }}\right)$ calculated by using semiempirical expressions and those $\left(E_{\text {expl }}\right)$ derived from the analysis of the experimental data on some relevant conformation-dependent properties such as the unperturbed dimension, dipole moment, and bond conformations.

In the case of poly(oxyethylene) (POE), ${ }^{5,9,10}$ where $R_{1}=R_{2}=H$, semiempirical energy calculations failed to reproduce the observed preference for the gauche over the trans state. The theoretical value is $0.6 \mathrm{kcal} \mathrm{mol}^{-1}(1 \mathrm{cal}=4.2 \mathrm{~J})$ in favor of the 
trans state in opposition to that $\left(-0.4 \mathrm{kcal} \mathrm{mol}^{-1}\right)$ estimated from the experimental data. A similar gauche oxygen effect has been reported by Zefirov $e t$ $a l .{ }^{11}$ from studies on 1,2-disubstituted cyclohexanes. Poly(oxypropylene) (POP), ${ }^{6}$ the second member of the series $\left(\mathrm{R}_{1}=\mathrm{H}, \mathrm{R}_{2}=\mathrm{CH}_{3}\right)$, carries an asymmetric carbon atom in each repeat unit. In this polymer system, therefore, two gauche states occurring around a skeletal $\mathrm{C}-\mathrm{C}$ bond are sterically unequivalent to each other. The gauche oxygen effect estimated for the $g_{\alpha}$ conformation, in which the articulated methyl group is situated trans to the preceding oxygen, is in the same order of magnitude as that of POE. Such a stabilization effect, however, was found to be largely suppressed in the sterically more hindered $g_{\beta}$ conformation, in which the preceding oxygen atom is $s y n$ to both the following oxygen and the methyl group. These observations were further supported by the conformational studies reported by Shinbo et al. ${ }^{12}$ on 2-methoxymethyltetrahydropyran:

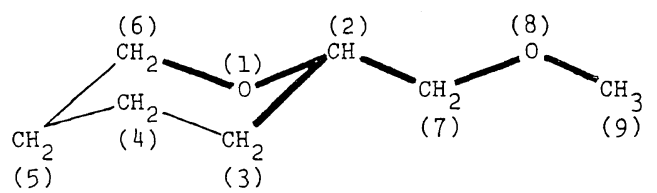

Here the portion shown by the heavy solid lines simulates the skeletal structure of POP. The articulated $\mathrm{C}_{2}-\mathrm{C}_{7}$ bond occupies preferentially the equa- torial position. Fractions of the three conformers permitted to the $\mathrm{C}_{2}-\mathrm{C}_{7}$ bond were estimated by the dipole moment and ${ }^{1} \mathrm{H}$ NMR measurements. The results were favorably interpreted by taking into account the gauche oxygen effects comparable in magnitude with those found in POP.

Substitution of another methyl group on the $\mathrm{C}_{1}$ atom of POP leads to PODME $\left(\mathrm{R}_{1}=\mathrm{R}_{2}=\mathrm{CH}_{3}\right)$. High molecular weight PODME has not been studied extensively with regard to its configurational characteristics because of its low solubility in usual organic solvents. As inspection of a molecular model reveals, however, studies on 1,2-dimethoxy-2-methylpropane (DMMP), a monomer model $(x=1)$, may provide alternatively the relevant information regarding the rotational isomerism around the $\mathrm{C}-\mathrm{C}$ bond. This paper presents the results of dielectric measurements for DMMP in various nonpolar solvents, and the values of the conformational energies estimated therefrom. The conformational analysis of DMMP and PODME based on the ${ }^{13} \mathrm{C}-{ }^{1} \mathrm{H}$ vicinal coupling constant data will be reported in the following article.

\section{EXPERIMENTAL}

\section{Material}

Preparation of DMMP was carried out according to the scheme ${ }^{13}$ :

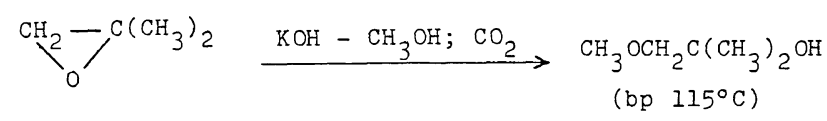

$$
\begin{aligned}
& \text { (I) } \\
& \underset{\mathrm{NaH}, \mathrm{CH}_{3} \mathrm{I}}{\longrightarrow} \underset{\left(\text { bp } 110^{\circ} \mathrm{C}\right)}{\mathrm{CH}_{3} \mathrm{OCH}_{2} \mathrm{C}\left(\mathrm{CH}_{3}\right)_{2} \mathrm{OCH}_{3}}
\end{aligned}
$$

The starting material, 1,2-epoxy-2-methylpropane, was supplied by Daicel Co. DMMP (II) obtained above was purified by repeating fractional distillation. A fraction having a purity higher than $99 \%$ (by the gas chromatography) was adopted for the dipole moment measurements.

\section{Dipole Moment Determination}

Dielectric measurements were performed at $1 \mathrm{MHz}$ using a conventional heterodyne beat apparatus. Freshly distilled reagent grade benzene, cyclohexane, and carbon tetrachloride were used as solvents. The instrument was calibrated against the established values of the dielectric constants of the pure solvents. Values adopted for $25^{\circ} \mathrm{C}$ are as follows ${ }^{14}$ : benzene 2.274, cyclohexane 2.015 , and carbon tetrachloride 2.228. The measurements were carried out at four concentrations for each solvent system. The densities of solutions required in the Halverstadt-Kumler treatment ${ }^{15}$ were measured with a precision density meter DMA02C (manufactured by Anton Paar Co.). The root-mean-square dipole moments $\left\langle\mu^{2}\right\rangle^{1 / 2}$ were calculated from the observed dielectric constants according to the stan- 
Configurational Characteristics of PODME. I.

Table I. Results of dielectric measurements $\left(25^{\circ} \mathrm{C}\right)$

\begin{tabular}{lccc}
\hline & Benzene & $\begin{array}{c}\text { Carbon } \\
\text { tetrachloride }\end{array}$ & Cyclohexane \\
\hline$\varepsilon_{0}$ & 2.27 & 2.23 & 2.02 \\
$(\mathrm{~d} \varepsilon / \mathrm{d} \omega)$ & $2.3_{4}$ & $4.1_{9}$ & $1.8_{1}$ \\
$10^{3} \rho_{0} / \mathrm{kg} \mathrm{m}^{-3}$ & 0.871 & $1.58_{4}$ & 0.773 \\
$10^{3}(\mathrm{~d} \rho / \mathrm{d} \omega) / \mathrm{kg} \mathrm{m}^{-3}$ & -0.03 & $-1.3_{5}$ & $0.0_{5}$ \\
$\left\langle\mu^{2}\right\rangle^{1 / 2} / D$ & $1.69 \pm 0.04$ & $1.68 \pm 0.03$ & $1.61 \pm 0.05$ \\
$\left\langle\mu^{2}\right\rangle / n m^{2}$ & $0.58 \pm 0.02$ & $0.56 \pm 0.01$ & $0.52 \pm 0.02$ \\
\hline
\end{tabular}

dard expressions

$$
\left\langle\mu^{2}\right\rangle^{1 / 2}=0.0128 \sqrt{\left(p-1.05 R_{\mathrm{D}}\right) T}
$$

and

$$
p=M \frac{\varepsilon_{0}-1}{\varepsilon_{0}+2} \frac{1}{\rho_{0}}\left(1+\frac{3(\mathrm{~d} \varepsilon / \mathrm{d} \omega)}{\left(\varepsilon_{0}-1\right)\left(\varepsilon_{0}+2\right)}-\frac{(\mathrm{d} \rho / \mathrm{d} \omega)}{\rho_{0}}\right)
$$

where $p$ is the molar polarization, $R_{\mathrm{D}}$ the molar refractivity $\left(3.35 \times 10^{-5} \mathrm{~m}^{3}\right)^{16}, T$ the absolute temperature, $M$ the molar mass of the solute, $\varepsilon$ and $\varepsilon_{0}$ the dielectric constants of solution and solvent, respectively, $\omega$ the weight fraction of the solute, and $\rho$ and $\rho_{0}$ the densities of solution and solvent, respectively.

\section{RESULTS}

Experimental values of the coefficients $\mathrm{d} \varepsilon / \mathrm{d} \omega$ and $\mathrm{d} \rho / \mathrm{d} \omega$, obtained at $25^{\circ} \mathrm{C}$, and the RMS dipole moments $\left\langle\mu^{2}\right\rangle^{1 / 2}$ calculated therefrom are given in Table I, where the values of $\varepsilon_{0}$ and $\rho_{0}$ used in the calculations are also included. For later convenience, the results were recast into the dipole moment ratio $\left\langle\mu^{2}\right\rangle / \mathrm{nm}^{2}$, where $n$ is the number of the skeletal bonds, and $m^{2}$ is the mean-square of the bond moments of the molecule: for DMMP, $n=5$ and $m^{2}=0.996$ ( $c f$. seq.), the unit of $m$ being expressed in Debye $\left(3.34 \times 10^{-30} \mathrm{Cm}\right)$.

Variation of the dipole moment with temperature was studied over the range $25-40^{\circ} \mathrm{C}$. From the plot $\ln \left[\left\langle\mu^{2}\right\rangle / n m^{2}\right] \quad v s$. temperature, the thermal coefficients $\mathrm{d} \ln \left\langle\mu^{2}\right\rangle / \mathrm{d} T$ were estimated to be 3.5 $( \pm 3.8) \times 10^{-3}$ (benzene), $1.7( \pm 2.9) \times 10^{-3}$ (carbon tetrachloride), and $4.4( \pm 4.8) \times 10^{-3} \mathrm{~K}^{-1}$ (cyclohexane). The range of temperature over which these experiments were carried out is insufficient to claim much precision for the results.

\section{CONFORMATIONAL ANALYSIS OF DMMP}

A schematic representation of DMMP in its all trans conformation is given in Figure 1, where skeletal bonds and bond angles are numbered from left to right. The bond lengths and bond angles used in this study are listed in Table II. The two bond angles $\operatorname{COC}$ denoted by $\theta_{1}$ and $\theta_{4}$ may not be sterically equivalent. A value of $111.5^{\circ}$ was assigned to the former $\left(\theta_{1}\right)$, the same value being used previously in the treatment of the $\mathrm{POE}^{5}$ and POP chains. ${ }^{6}$ A somewhat larger bond angle $118^{\circ}$ was

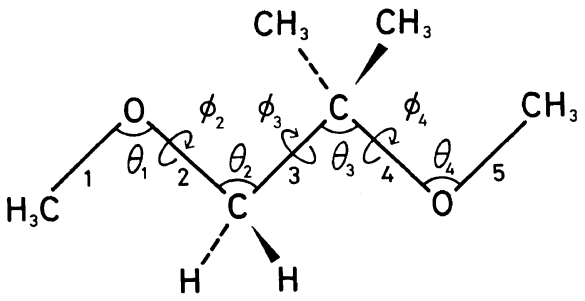

Figure 1. Schematic diagram of 1,2-dimethoxy-2methylpropane (DMMP) in its extended form, a monomer model for the poly(oxy-1,1-dimethylethylene) (PODME) chain.

Table II. Geometrical parameters used

\begin{tabular}{|c|c|c|c|}
\hline \multicolumn{2}{|c|}{ Bond length } & \multicolumn{2}{|c|}{ Bond angle } \\
\hline \multicolumn{2}{|c|}{$\AA$} & \multicolumn{2}{|c|}{$\operatorname{deg}$} \\
\hline $\mathrm{C}-\mathrm{C}$ & 1.53 & $\theta_{1}$ & 111.5 \\
\hline $\mathrm{C}-\mathrm{O}$ & 1.43 & $\theta_{2}$ & 112 \\
\hline \multirow[t]{4}{*}{$\mathrm{C}-\mathrm{H}$} & 1.10 & $\theta_{3}$ & 109.5 \\
\hline & & $\theta_{4}$ & 118 \\
\hline & & $\angle \mathrm{CCH}$ & 110 \\
\hline & & $\angle \mathrm{OCH}$ & 110 \\
\hline
\end{tabular}
for DMMP 
adopted for the latter $\left(\theta_{4}\right)$ in consideration of the results of the conformational analysis presented in a later part of this section. The bond angles at the carbon atom carrying two methyl substituents may be assumed to be tetrahedral. The angle OCC at the primary carbon atom was taken to be $112^{\circ} .{ }^{5}$

Following the procedure customarily employed in the conformational statistics of chain molecules, ${ }^{17}$ statistical weight matrices may be defined for the three internal bonds of the DMMP molecule as

$$
\begin{aligned}
& \boldsymbol{U}_{2}=\left[\begin{array}{ccc}
1 & \sigma^{\prime} & \sigma^{\prime}
\end{array}\right] \\
& \boldsymbol{U}_{3}=\left[\begin{array}{ccc}
1 & \sigma & \sigma \\
0 & 0 & \sigma \omega \\
0 & \sigma \omega & 0
\end{array}\right] \\
& \boldsymbol{U}_{4}=\left[\begin{array}{ccc}
1 & 1 & 1 \\
1 & 1 & \omega^{\prime} \\
1 & \omega^{\prime} & 1
\end{array}\right]
\end{aligned}
$$

where subscripts specify the bond with which the corresponding statistical weight matrix is associated, and rows and columns of each matrix are indexed to rotational states in the order $t, g^{+}$, and $g^{-}$for the bond pair under consideration. Since it is not necessary to define the rotational isomeric states for the first bond, $\boldsymbol{U}_{2}$ may be expressed in a row form. Statistical weight parameters $\sigma^{\prime}$ and $\sigma$ are defined respectively for the first-order interactions ${ }^{17}$ taking place about bonds 2 and 3. Similarly, $\omega$ and $\omega^{\prime}$ are those for the second-order interactions as specified. Each statistical weight factor is normalized to the weight of unity for the corresponding trans state. Following the conventional procedure, ${ }^{17}$ statistical weight parameters are taken to be simple Boltzmann factors in the corresponding conformational energies. With the statistical weight matrices thus defined, the configurational partition function $Z$ for DMMP can be given by ${ }^{17}$

$$
Z=U_{2} U_{3} U_{4} J
$$

where $J$ is a $3 \times 1$ column matrix with all elements equal to unity.

Theoretical values of the conformational energies were calculated as a function of bond rotation angles by adopting the expressions used previously for the analyses of polyoxide chains. ${ }^{5-8}$ As inspection of a model reveals, rotation around bond 4 involves severe steric repulsions between the terminal methyl and the preceding methyl or methylene groups irrespective of the rotational isomeric states. The bond angle $\theta_{4}$ tends to be widened by such steric effects. However, the angle deformation thus induced must be opposed by the angle strain energy customarily expressed ${ }^{18}$ as

$$
E(\theta)=A(\pi / 180)^{2}\left(\theta_{4}-109.5\right)^{2}
$$

Following Shimanouchi et al., ${ }^{19}$ the force constant $A$ for the $\angle$ COC bending was taken to be $88 \mathrm{kcal}$ $\mathrm{mol}^{-1}$. The equilibrium position for $\theta_{4}$ was estimated by calculating the conformational energy as a function of $\theta_{4}$, the other bond angles being kept invariable. When all the internal bonds are kept trans $\left(\phi_{2}=\phi_{3}=\phi_{4}=0\right)$, the energy was found to be minimum at about $\theta_{4}=118.6^{\circ}$. This value reduces slightly to $117.4^{\circ}$ if adjustments of rotation angles $\left(\phi_{s}\right)$ for the articulated methyl groups are additionally permitted: displacements of $\Delta \phi_{\mathrm{s}}=6^{\circ}$ from the regularly staggered position are required. We adopt a value of $118^{\circ}$ in Table II and also in the following study.

In the previous treatment of $\mathrm{POE}^{5}$ and $\mathrm{POP}^{6}$, a value of $1.20( \pm 0.10) \mathrm{D}$ was set forth for the dipole moment of the ether group. According to McClellan's table ${ }^{20}$ the dipole moment of methyl $t$ butyl ether, a model for the $-\mathrm{CH}_{2} \mathrm{C}\left(\mathrm{CH}_{3}\right)_{2} \mathrm{OCH}_{2}-$ moiety, was found to be similar in magnitude, indicating that the dipole moment of the aliphatic ether is not affected much by the bulkiness of the alkyl groups. In view of these experimental observations, we adopt an identical value $(1.20 \pm 0.10 \mathrm{D})$ for both ether groups of DMMP. The combined use of the bond angle $\theta_{4}=118^{\circ}$ (see above) leads to a value of $1.16 \mathrm{D}$ for the bond dipole moment applicable to bonds 4 and 5. The corresponding partial electronic charges assigned to the carbon and oxygen atoms are respectively $\delta_{\mathrm{C}}=0.17$ and $\delta_{\mathrm{O}}=-0.34$.

Using the set of geometrical parameters given in Table II, we calculated energies for several representative conformations. Locations of the energy minima and the associated energies (expressed relative to the $t t t$ state) are summarized in Table III. Statistical weight factors assigned to these conformations are also given in the preceding column. The separate interaction energies were deduced from 
Table III. Results of semiempirical energy calculations for DMMP: low-energy conformations, their statistical weight factors, locations of energy minima, and separate interaction energies

\begin{tabular}{|c|c|c|c|c|c|c|}
\hline \multirow{2}{*}{ Conformation } & \multirow{2}{*}{$\begin{array}{c}\text { Statistical } \\
\text { weight factor }\end{array}$} & $\phi_{2}$ & $\phi_{3}$ & $\phi_{4}$ & $E_{\min }$ & \multirow{2}{*}{$\begin{array}{l}\text { Conformational } \\
\text { energy parameter }\end{array}$} \\
\hline & & deg & $\operatorname{deg}$ & deg & $\mathrm{kcal} \mathrm{mol}^{-1}$ & \\
\hline$t \quad t g^{ \pm}$ & $\gamma$ & 0 & \pm 4 & \pm 118 & 0.1 & $E_{\gamma}=0.1$ \\
\hline$t g^{ \pm} t$ & $\sigma$ & 0 & $\pm \overline{120}$ & 0 & 0.5 & $E_{\sigma}=0.5$ \\
\hline$t g^{ \pm} g^{\mp}$ & $\sigma \gamma \omega^{\prime}$ & 0 & \pm 102 & $\mp 121$ & 1.5 & $E_{\omega \prime}=0.9^{\mathrm{a}}$ \\
\hline$t g^{ \pm} g^{ \pm}$ & $\sigma \gamma$ & 0 & \pm 122 & \pm 120 & 0.6 & \\
\hline$g^{ \pm} g^{\mp} t$ & $\sigma^{\prime} \sigma \omega$ & \pm 87 & $\bar{\mp} 116$ & 0 & 2.0 & $E_{\sigma^{\prime}}+E_{\omega}=1.5^{\mathrm{b}}$ \\
\hline
\end{tabular}

${ }^{\mathrm{a}} E_{\omega}=E_{t g \pm g} \mp-E_{\sigma}-E_{\gamma} . \quad{ }^{\mathrm{b}} E_{\sigma},+E_{\omega}=E_{g \pm g} \mp_{t}-E_{\sigma}$.

these results in a usual manner, ${ }^{5}$ and are listed in the last column of the table. The theoretical value of $E_{\sigma}$ estimated in this manner is $0.5 \mathrm{kcal} \mathrm{mol}^{-1}$. In the following section, the parameter $E_{\sigma}$ is alternatively determined so as to reproduce the observed values of the dipole moment. Contributions from the $g^{ \pm} t$ and $g^{ \pm} g^{ \pm}$conformations for the bond pair $(2,3)$ are entirely neglected in consideration of the very severe steric conflicts taking place between the terminal methyl and one of the articulated methyl groups. Steric repulsions become less severe in the $g^{ \pm} g^{\mp}$ states for the same bond pair: in this conformation, the articulated methyl group mentioned above is replaced by the oxygen atom of the skeletal chain. The sum of the conformational energies $E_{\sigma}$, and $E_{\omega}$ is the relative energy assigned to these states and can be obtained from the calculation for the $g^{ \pm} g^{\mp} t$ conformation ( $c f$. Table III). As is evident from the expression given in eq 3 and 4 , a further separation of the energy parameter into $E_{\sigma}$, and $E_{\omega}$ is unnecessary in the present treatment. If a value of $1.2-1.3 \mathrm{kcal} \mathrm{mol}^{-1}$ is assigned ${ }^{5,6}$ to $E_{\sigma}$, however, the other parameter $E_{\omega}$ should bear 0.2 to $0.3 \mathrm{kcal}$ $\mathrm{mol}^{-1}$, a similar value being adopted in the analysis of the POE chain. ${ }^{5}$ The parameter $E_{\gamma}$ comprises mainly the electrostatic contribution involved in the $g^{ \pm}$conformation about bond 3 . An increment in energy from this source was estimated to be only 0.1 $\mathrm{kcal} \mathrm{mol}^{-1}$. Accordingly, the statistical weight of unity is assigned to these states $(\gamma=1)$ in the following treatment.

\section{ESTIMATION OF $E_{\sigma}$ FROM THE ANALYSIS OF THE DIPOLE MOMENT DATA}

The values of $\left\langle\mu^{2}\right\rangle / n m^{2}$ were computed for the

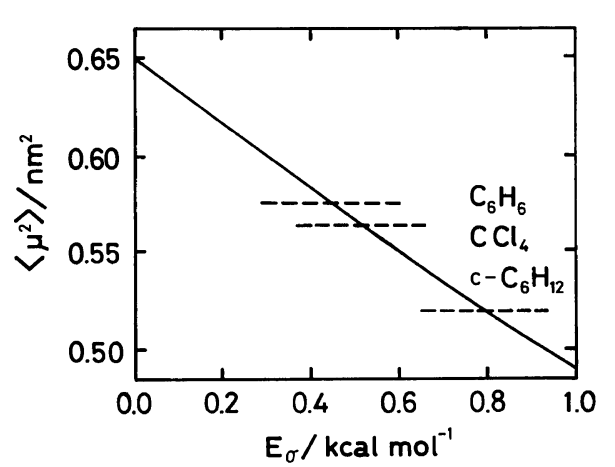

Figure 2. The dipole moment ratio for DMMP calculated as a function of $E_{\sigma}$ for the temperature of $25^{\circ} \mathrm{C}$. The horizontal dashed lines specify the experimental values observed in the solvents indicated.

geometry given in Table II according to the conventional procedure. ${ }^{17}$ The bond dipole moments for the $\mathrm{C}-\mathrm{O}$ bonds were assumed to be $1.07 \mathrm{D}$ for the ether group associated with the primary carbon atom (bonds 1 and 2), and 1.16 D for that of the tertiary "carbon atom (bonds 4 and 5). The bond dipole moment for the $\mathrm{C}-\mathrm{C}$ bond was assumed to be null. ${ }^{5-8}$ Results of calculations for the temperature of $25^{\circ} \mathrm{C}$ are shown in Figure 2 as a function of $E_{\sigma}$ over a range $0-1.0 \mathrm{kcal} \mathrm{mol}^{-1}$. Conformational energy parameters required in these calculations (other than $E_{\sigma}$ ) were deduced in the preceding section. Also shown in Figure 2 are the experimental values of $\left\langle\mu^{2}\right\rangle / \mathrm{nm}^{2}$ (the dashed lines) observed in the solvents as indicated. The values of $E_{\sigma}$ which reproduce these experimental observations are as follows; $0.4 \pm 0.1$ (benzene), $0.5 \pm 0.1$ (carbon tetrachloride), and $0.8 \pm 0.1$ (cyclohexane), units being $\mathrm{kcal} \mathrm{mol}^{-1}$. The temperature coefficient $\mathrm{d} \ln \left\langle\mu^{2}\right\rangle / \mathrm{d} T$ calculated by using $E_{\sigma}=0.5 \mathrm{kcal} \mathrm{mol}^{-1}$ is $0.5 \times 10^{-3}$ 
$\mathrm{K}^{-1}\left(30^{\circ} \mathrm{C}\right)$. Positive values of the temperature coefficient were suggested from studies over the range $25-40^{\circ} \mathrm{C}$. Experimental uncertainties involved in the measurements are however too large to allow a quantitative comparison (see above).

\section{DISCUSSION}

The conformational energy parameter $E_{\sigma}$ deduced from the analysis of the experimental values of the dipole moment was found to be in the range $0.4-0.8 \mathrm{kcal} \mathrm{mol}^{-1}$, indicating that the trans form is more stable than the gauche arrangement for the moiety $\mathrm{O}-\mathrm{CH}_{2}-\mathrm{C}\left(\mathrm{CH}_{3}\right)_{2}-\mathrm{O}$. The theoretical value of the same energy obtained in the previous section is $0.5 \mathrm{kcal} \mathrm{mol}^{-1}$ (Table III). The close agreement between theory and experiment as seen above suggests that the gauche oxygen effect ${ }^{11,21}$ is nearly suppressed in DMMP.

Observed values of the dipole moment ratio $\left\langle\mu^{2}\right\rangle / n m^{2}$ for 1,2-dimethoxyethane (DME) ${ }^{22}$ and 1,2-dimethoxypropane (DMP) ${ }^{23}$ were reported to be in the range $0.55-0.64$ and $0.54-0.59$, respectively. These values were favorably reproduced by calculations carried out using conformational energy parameters derived from the analysis of various configuration-dependent properties of the polymers. The corresponding values for DMMP were found to be $0.52-0.57$ as given in Table I. In this series of compounds, which may be represented by a general formula $\mathrm{CH}_{3} \mathrm{OCH}_{2} \mathrm{C}\left(\mathrm{R}_{1}\right)\left(\mathrm{R}_{2}\right) \mathrm{OCH}_{3}$, the internal rotation for the central $\mathrm{C}-\mathrm{C}$ bond tends to be more restricted in the order DME $\left(\mathrm{R}_{1}=\mathrm{R}_{2}=\mathrm{H}\right),{ }^{5}$ DMP $\left(\mathrm{R}_{1}=\mathrm{H}, \mathrm{R}_{2}=\mathrm{CH}_{3}\right),{ }^{6}$ and DMMP $\left(\mathrm{R}_{1}=\mathrm{R}_{2}=\mathrm{CH}_{3}\right)$, while that for the succeeding $\mathrm{C}-\mathrm{O}$ bond follows the opposite trend. In spite of these variations in conformational aspects, the values of the square of the dipole moment averaged over all conformations remain quite invariable for the class of molecules under consideration. The same seems to hold for the temperature coefficient $\mathrm{d} \ln \left\langle\mu^{2}\right\rangle / \mathrm{d} T$.

The statistical weight matrices $\boldsymbol{U}_{1}$ and $\boldsymbol{U}_{2}$ defined respectively by eq 3 and 4 should be applicable, as they stand, to the 2 nd and $3 \mathrm{rd}$ bond of the polymeric chain $\mathrm{CH}_{3} \mathrm{O} f \mathrm{CH}_{2} \mathrm{C}\left(\mathrm{CH}_{3}\right)_{2} \mathrm{O}_{x} \mathrm{CH}_{3}$. The repeat unit of the chain comprises three bonds: (a) $\mathrm{CH}_{2}-\mathrm{C}\left(\mathrm{CH}_{3}\right)_{2}$, (b) $\mathrm{C}\left(\mathrm{CH}_{3}\right)_{2}-\mathrm{O}$, and (c) $\mathrm{O}-\mathrm{CH}_{2}$. Due to very severe steric conflicts associated with the interaction taking place between the two
$\mathrm{C}\left(\mathrm{CH}_{3}\right)_{2}$ groups, both gauche states for the $\mathrm{O}-\mathrm{CH}_{2}$ bond may be entirely suppressed: the trans state remains to be the only choice for the bond. Thus we have a column expression for bond $\mathrm{c}$ :

$$
U_{\mathrm{c}}=\left[\begin{array}{l}
1 \\
1 \\
1
\end{array}\right]
$$

and consequently, a row form for bond a:

$$
\boldsymbol{U}_{\mathrm{a}}=\left[\begin{array}{lll}
1 & \sigma & \sigma
\end{array}\right]
$$

The matrix $\boldsymbol{U}_{4}$ in eq 5 is effective, without any modification, for all internal $\mathrm{CH}_{2}-\mathrm{O}$ bonds (i.e. bond $b$ ):

$$
\boldsymbol{U}_{\mathrm{b}}=\boldsymbol{U}_{4}
$$

The statistical weight matrices having been defined in this manner, conformational energy parameters obtained from the analysis of DMMP should serve for the theoretical estimation of various configuration-dependent properties of the PODME chain. This subject will be treated in paper III.

Acknowledgment. The authors wish to thank Dr. K. Tanaka of Daicel Co. Ltd. for kindly providing the samples used in this study.

\section{REFERENCES}

1. J. Boor and R. S. Bauer, J. Appl. Polym. Sci., 18, 3699 (1974).

2. T. Yamazaki, S. Oya, N. Tsukane, K. Tanaka, H. Toba, and K. Yamagishi, Polymer, 16, 425 (1975).

3. J. Furukawa in "Encyclopedia of Polymer Science and Technology," Vol. 6, John Wiley, New York, 1967, p 191.

4. K. Kaji and I. Sakurada, Makromol. Chem., 148, 261 (1971); I. Sakurada and K. Kaji, J. Polym. Sci., C31, 57 (1970).

5. A. Abe and J. E. Mark, J. Am. Chem. Soc., 98, 6468 (1976).

6. A. Abe, T. Hirano, and T. Tsuruta, Macromolecules, 12, 1092 (1979).

7. A. Abe, T. Hirano, K. Tsuji, and T. Tsuruta, Macromolecules, 12, 1100 (1979).

8. A. Abe, J. Am. Chem. Soc., 98, 6477 (1976).

9. J. E. Mark and P. J. Flory, J. Am. Chem. Soc., 87, 1415 (1965); ibid., 88, 3702 (1966); G. D. Patterson and P. J. Flory, J. Chem. Soc., Faraday Trans. 2, 68, 1111 (1972).

10. K. Bak, G. Elefante, and J. E. Mark, J. Phys. Chem., 


\section{Configurational Characteristics of PODME. I.}

71, 4007 (1967).

11. N. S. Zefirov, L. G. Gurvich, A. S. Shashkov, M. Z. Krimer, and E. A. Vorob'eva, Tetrahedron, 32, 1211 (1976).

12. Y. Shinbo, H. Koinuma, T. Hirano, T. Tsuruta, and A. Abe, Polym. Prepr., Jpn., 28, 501 (1980).

13. L. H. Horsley and P. S. Petrie, U.S. Patent $2,886,600$ (1959).

14. N. Koizumi in "Shin Jikken Kagaku Koza," Vol. 5, The Chemical Society of Japan, Ed., Maruzen Co., Tokyo, 1976, Section 4, p 307.

15. I. F. Halverstadt and W. D. Kumler, J. Am. Chem. Soc., 64, 2988 (1942).

16. J. W. Smith, "Electric Dipole Moments," Butterworths, London, 1955, p 356.

17. P. J. Flory, "Statistical Mechanics of Chain
Molecules," Intersceince, New York, 1969.

18. M. Bixon and S. Lifson, Tetrahedron, 23, 769 (1967).

19. T. Shimanouchi, H. Matsuura; Y. Ogawa, and I. Harada, J. Phys. Chem. Ref. Data, 7, 1323 (1978).

20. A. L. McClellan, "Tables of Experimental Dipole Moments," Vol. 1, W. H. Freeman, San Francisco, Calif., 1963; Vol. 2, Rahara Enterprises, El Cerrito, Calif., 1974.

21. S. Wolfe, Acc. Chem. Res., 5, 102 (1972).

22. K. Kimura and R. Fujishiro, Bull. Chem. Soc. Jpn., 39, 608 (1966).

23. T. Hirano, P. H. Khanh, K. Tsuji, A. Sato, T. Tsuruta, A. Abe, T. Shimozawa, A. Kotera, N. Yamaguchi, and S. Kitahara, Polym. J., 11, 905 (1979) 